\title{
La cultura física debe integrarse con otras disciplinas
}

Fabio Barbosa

Programa de Educación Física

Mucho se ha pensado y meditado para resolver el atraso que en materia deportiva y competitiva se tiene en Colombia. Pero mientras no se resuelvan problemas como la abundacia de hurocracia deportiva, la deficiente utilización de los escenarios, la falta de escuelas, de programaciones continuas y extensas por parte de ligas y federaciones, de capacitación y actualización de técnicos y monitores, la inexistencia de vínculos de cooperación, asesoría e intercambio de propuestas tendientes a formar, fomentar y cualificar el deporte en las regiones donde por suerte se cuenta con Programas de Educación Física a nivel Universitario, y la apatia de las Asociaciones de Educadores Físicos por integrarse a la realidad sociodeportiva del pais, que no les han permitido tomar conciencia del rol que deben cumplir en el proceso formativo del deportista competitivo, recreativo, participativo y campeón.

La Nueva Ley que pronto regirá el deporte en general, reconoce abiertamente que Coldeportes tuvo una orientación equivocada, que la promoción deportiva no ha contado con la atención suficiente por parte de ninguna de las instituciones encargadas de mantener vivo el deseo por su práctica, y que son cosas diferentes la Educación Física es al Ministerio de Educación Nacional.

Lo que no se puede seguir afirmando, es que la Educación Fisica es responsable directa de la abundancia o no de elementos técnicos depurados en los jóvenes deportistas, porque si bien utiliza el movimiento humano en general y la fundamentación deportiva en particular, su fin primordial es formar al individuodel mañana en su carácter, personalidad, sociabilidad y capacidad recreativa; que se sea apto para disfrutar en la práctica los deportes, porque los conocen y dominan medianamente sus fundamentos técnicos. Además, dos periodos de clases semanales no son suficientes para mejorar y depurar los movimientos técnicos de un deporte, ello se logra gracias al trabajo dirigido (puede ser un Profesional de la
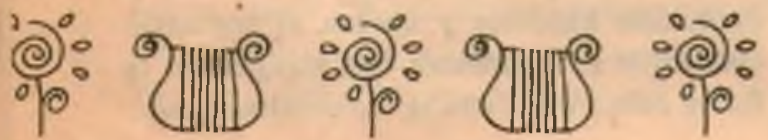
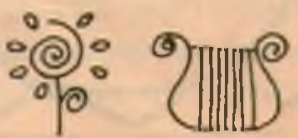
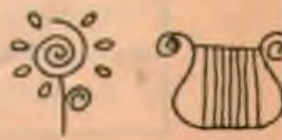
E.F.) minimo de unas cuatro horas diarias de adiestramiento téenico-deportivo.

Para conseguir deportistas de alto rendimiento se debe proporcionar en primera instancia gran riqueza motriz, porque es de aquí en donde surge la capacidad dominadora de la destreza deportiva y nada mejor para lograr la diversidad y afianzamiento de las técnicas básicas del movimiento, que la gimnasia y el atletismo en los primeros años de vida deportiva.

\section{Nuevos Horizontes}

Algunos creen que el ejercicio físico, el juego y el deporte tienen como único objetivo mantener el cuerpo fuerte y conservar la salud, otros piensan únicamente desde la óptica del rendimiento deportivo, es decir, el ejercicio físico como medio principal para obtener la depuración técnica junto con el rendimiento físico atlético, también quienes lo toman desde el punto de vista de la pedagogía y resaltan el componente físico porque "todas las tareas gimnásticas y deportivas no son una finalidad en sí mismas, sino que están al servicio de la conducta del hombre. mientras más cualificados sean el juego y los ejercicios fúsicos, mayores serán sus posibilidades de formacion. "*

Para otros, lo principal es la ocupación del tiempo libre en actividades que distraigan de los problemas y ocupaciones cotidianas, y finalmente, los que integran los aspectos mencionados, que le da a la Educación Física, una extensión considerable en campos de ocupación laboral.
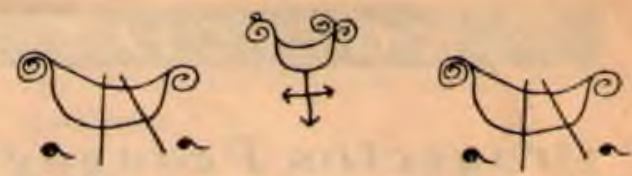

La anteriormente escrito junto con la inclinación de la moda y el reconocimiento al cuerpo como parte fundamental de la existencia del hombre, han hecho posible que en la actualidad se adopte una noción más amplia del hombre en movimiento, por eso se comienza a designar como cultura física, todo aquello que esté relacionado con la actividad lúdrica-recreativa y físicoatlética del hombre.

La tarea por emprender es entonces, buscar los límites de la cultura física, por que aquí caben muchas actividades que ya pertenecen a otras ciencias y oficios, pero que por tener una relación directa con las acciones móviles del hombre, se pueden considerar como de nueva pertenencia. Por ahora, lo más sensato y conveniente es proseguir estrechando la relación con las otras ciencias y disciplinas, en procura de mejorar las satisfacciones proporcionadas por la nueva rama de la cultura.

La cultura física está representando ahora para el nuevo profesional del área, la oportunidad de cambiar su tradicional ocupación (docente) por otra cualquiera de las tantas que se han formado gracias a la interacción de las profesiones, ciencias y disciplinas con la Educación Física, Vg. administradores, promotores y entrenadores deportivos; rehabitadores físicos; recreacionistas; propietarios de centros recreativos-deportivos y constructores de implementos y aparatos deportivos.

* GRUPE, Ommo. Estudios sobre una teoría pedagógica de la Educación Fisica. pág. 49. 